\title{
Enhancing clinician and patient understanding of radiology reports: a scoping review of international guidelines
}

\author{
Caitlin I. Farmer ${ }^{1,2^{*}}$, Allison M. Bourne ${ }^{1,2}$, Denise O'Connor ${ }^{1,2}$, Jeffrey G. Jarvik ${ }^{3,4}$ and Rachelle Buchbinder ${ }^{1,2}$
}

\begin{abstract}
Imaging reports are the primary method of communicating diagnostic imaging findings between the radiologist and the referring clinician. Guidelines produced by professional bodies provide guidance on content and format of imaging reports, but the extent to which they consider comprehensibility for referring clinicians and their patients is unclear. The objective of this review was to determine the extent to which radiology reporting guidelines consider comprehensibility of imaging reports for referring clinicians and patients.

We performed a scoping review of English-language diagnostic imaging reporting guidelines. We searched electronic databases (OVID MEDLINE, Embase) and websites of radiological professional organisations to identify guidelines. The extent to which the guidelines recommended essential report features such as technical information, content, format and language, as well as features to enhance comprehensibility, such as lay language summaries, was recorded. Six guidelines from professional bodies representing radiologists from the USA, Canada, Australia and New Zealand, Hong Kong, the UK and Europe were identified from the search. Inconsistencies exist between guidelines in their recommendations, and they rarely consider that patients may read the report. No guideline made recommendations about the reporting of results considering the clinical context, and none recommended features preferred by patients such as lay language summaries. This review identifies an opportunity for future radiology reporting guidelines to give greater consideration to referring clinician and patient preferences.
\end{abstract}

Keywords: Comprehension, Diagnostic imaging, Guidelines as topic, Radiology, Review

\section{Key points}

- Radiology reporting guidelines produced by international radiology professional bodies are focused on technical detail and structure of the report.

- Radiology reports are increasingly accessed by a wide range of healthcare clinicians with varying levels of expertise, as well as patients themselves, and it is important they understand a report as it was intended.

\footnotetext{
* Correspondence: caitlin.farmer1@monash.edu

'Monash Department of Clinical Epidemiology, Cabrini Institute, 4 Drysdale

St, Malvern, VIC 3144, Australia

${ }^{2}$ Department of Epidemiology and Preventive Medicine, School of Public

Health and Preventive Medicine, Monash University, Melbourne, VIC, Australia

Full list of author information is available at the end of the article
}

- International guidelines rarely consider many of the preferences for radiology reporting expressed by referring clinicians and patients which may lead to confusion and anxiety.

\begin{abstract}
Introduction
Outside of hospital settings, where co-located clinicians and radiologists are able to more easily communicate, diagnostic imaging requests and reports are the primary means by which referring clinicians and the radiologists who report imaging findings communicate with each other [1]. The report may also be read by a range of other healthcare professionals with varying levels of experience and knowledge. It is therefore imperative that both the requests and reports are understood in the way
\end{abstract}

\section{Springer Open}

(ㅇ The Author(s). 2020 Open Access This article is licensed under a Creative Commons Attribution 4.0 International License, which permits use, sharing, adaptation, distribution and reproduction in any medium or format, as long as you give appropriate credit to the original author(s) and the source, provide a link to the Creative Commons licence, and indicate if changes were made. The images or other third party material in this article are included in the article's Creative Commons licence, unless indicated otherwise in a credit line to the material. If material is not included in the article's Creative Commons licence and your intended use is not permitted by statutory regulation or exceeds the permitted use, you will need to obtain permission directly from the copyright holder. To view a copy of this licence, visit http://creativecommons.org/licenses/by/4.0/. 
they are intended in order to inform appropriate clinical decisions.

It is widely accepted that diagnostic imaging reports must provide an accurate and detailed interpretation of the imaging findings. Less clear is exactly how that message should be communicated. Radiology reports vary widely in terms of phrasing, length and clarity [2], and there is growing evidence that referring clinicians and patients interpret ambiguous phrasing in radiology reports with more concern than radiologists, increasing patient anxiety and rates of follow-up testing [3]. In a study of 15 different phrases commonly used to convey the level of diagnostic certainty, radiologists and referring clinicians only agreed on one phrase ('diagnostic of') [4]. Along with diagnostic ambiguity, the use of more medical or precise terminology to describe a condition has been shown to lead to higher levels of patient anxiety, as well as perceptions of increased severity of the condition, and patient preference for more invasive treatments [5].

Professional member associations such as the American College of Radiology (ACR) [6] and the Australian and New Zealand College of Radiologists (RANZCR) [7] have guidelines regarding the content and structure of radiology reports. These guidelines aim to improve the quality and utility of imaging reports. The objective of this review was to determine the extent to which radiology reporting guidelines consider the preferences of the referring clinician and patient particularly with regard to comprehensibility of imaging reports.

\section{Methods}

\section{Design}

We conducted a scoping review using the methodology described by Arksey and O'Malley [8] and Levac et al. [9]. We reported our search and selection results according to the PRISMA Extension for Scoping Reviews (PRISMA-ScR) [10].

\section{Selection criteria}

We included all guidelines for communication of diagnostic imaging results created and published by a radiology professional body or a national member organisation and available in English. Guidelines in other languages without an official English translation were excluded as adequate translation services were not available; however, Google translate was used to identify potentially relevant publications in other languages. Publications from organisations other than radiology professional bodies, experimental studies, surveys, opinion pieces, editorials, guidelines regarding interventional radiology and guidelines on radiology research were also excluded as were research papers used to inform guidelines and condition-specific guidelines, such as the Thyroid Imaging Reporting and Data
System (TI-RADS) for reporting incidental thyroid nodules [11].

\section{Search methods for identifying guidelines}

We searched all 57 available websites of national member radiology societies associated with the International Society of Radiology (http://www.isradiology.org/2017/ isr/index.php). We also searched OVID MEDLINE and Embase from inception to 26 March 2019. The search strategy was developed in conjunction with an experienced librarian, and for MEDLINE, it was the following:

1. ((imag* or radiolog*) adj5 (result* or report* or record" or outcome*)).ti.

2. (Recommendation" or practice" or guideline* or guidance or standard" or protocol* or instruction* or information or method or convention).ti.

3. 1 and 2

4. Exp animals/ not humans.sh.

5. 3 not 4

The search strategy for Embase was similar except that line 4 was replaced with (exp animal/ or nonhuman/) not exp human/.

The reference lists of included guidelines and relevant articles were reviewed to identify additional guidelines. Only the most recent version of guidelines from each organisation was included.

\section{Screening and selection}

Two review authors (C.F. and A.B.) independently screened the titles and abstracts identified by the search. Full-text reports of potentially eligible guidelines were obtained and screened independently by two review authors (C.F. and A.B.). Discrepancies were to be resolved by discussion, but there was no discordance between reviewers. A PRISMA flow chart was developed to summarise the search and selection process (Fig. 1).

\section{Data extraction and synthesis}

A recent evidence-based guideline for the written radiology report that included a literature review, multi-disciplinary panel and public consultation [12] and which informed the RANZCR guidelines [12] was used as a template to extract recommendations for each guideline. This template can be grouped into four broad areas: technical information (patient demographics, comparison with prior studies, technique, procedural information, report status and examination quality), content (clinical information, relevant or abnormal findings, normal findings, addressing the clinical question, differential diagnosis, conclusion, recommendations for further testing or treatment and any discrepancy documentation), format (length, structured reporting, terminology for referring clinicians and patients, 


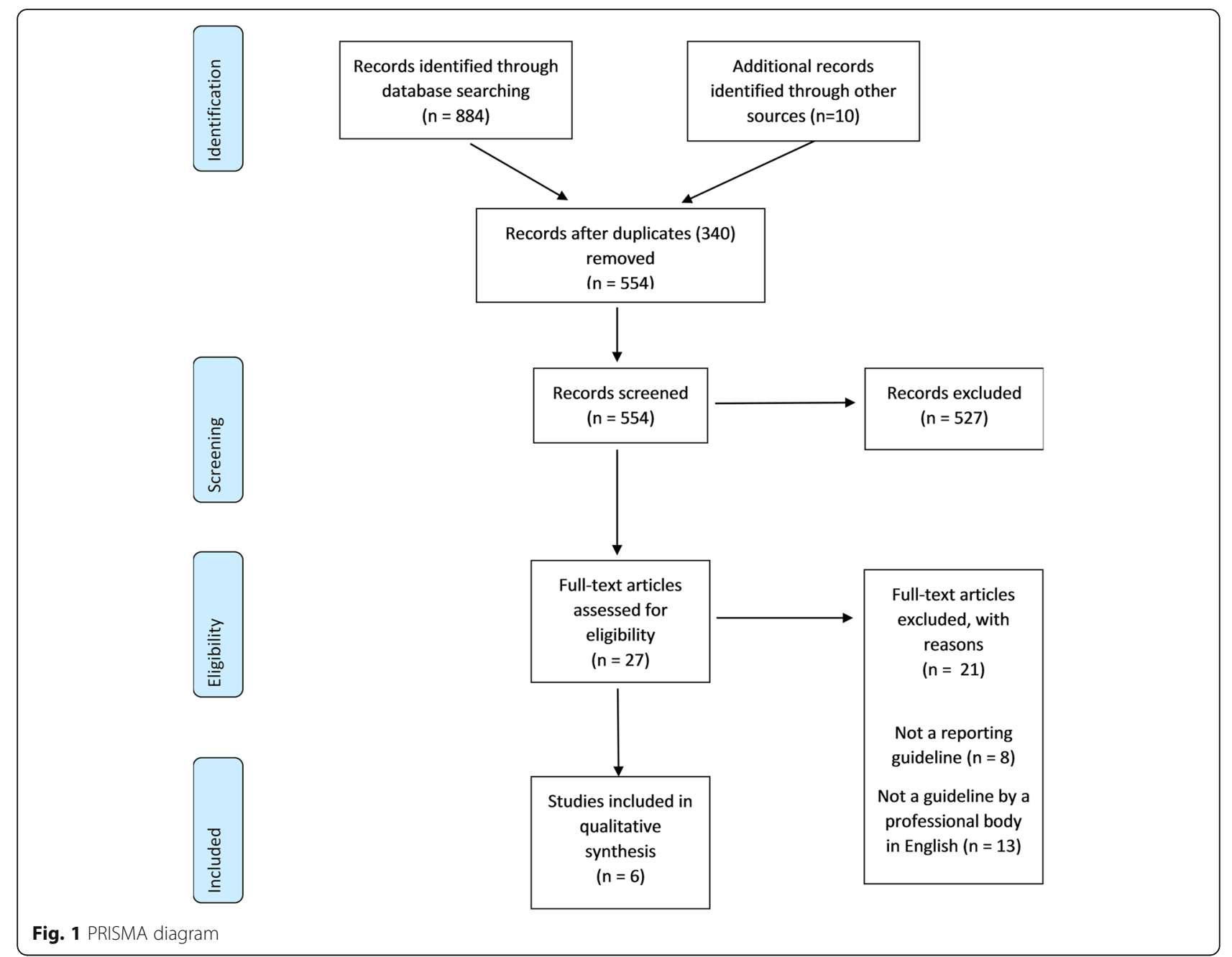

accuracy and 'actionable' reporting) and language (conveying confidence and certainty, clarity and readability).

In addition, we examined the included documents for any guidance regarding making reports more comprehensible to the clinician and/or patient, for example through suggesting lay summaries, altering or simplifying wording or provision of specific images or diagrams. Any specific advice regarding communication of findings and how this was conveyed (i.e. direct quotes) were also extracted. All findings were extracted and tabulated independently by two authors (C.F. and A.B.). Discordance was resolved by discussion and consensus.

\section{Results}

Of the 611 potentially eligible documents we identified, 27 were included for full-text review and six satisfied our eligibility criteria [6, 7, 13-16] (Fig. 1). A further four documents were identified on the websites of the Spanish Society of Medical Radiology, Italian Society of Radiology, Latvian Association of Radiologists and German Roentgen Society; however, these were excluded as no English language versions of these documents were available. The included documents comprised the guidelines from RANZCR [7], the UK Royal College of Radiologists (RCR) [13], the ACR [6], the Canadian Association of Radiologists (CAR) [16], the Hong Kong College of Radiologists (HKCR) [14] and the European Society of Radiology (ESR) [15]. Three guidelines were published in the last 2 years $[7,13,14]$. The ACR guidelines were revised most recently in 2014 and the ESR guidelines were published in 2011 and the CAR guidelines in 2010.

\section{Guideline development process}

Explanation regarding how each guideline was developed was variable (Table 1). All except the HKCR guidelines attributed development to committees, generally professional standards groups, and some named the individuals involved. The RANZCR guidelines state 'development was initially achieved by a multi-disciplinary team using a transparent and documented process of integration of evidence with expert opinion'. This is presumed to refer to an initial literature review [17] which informed a 


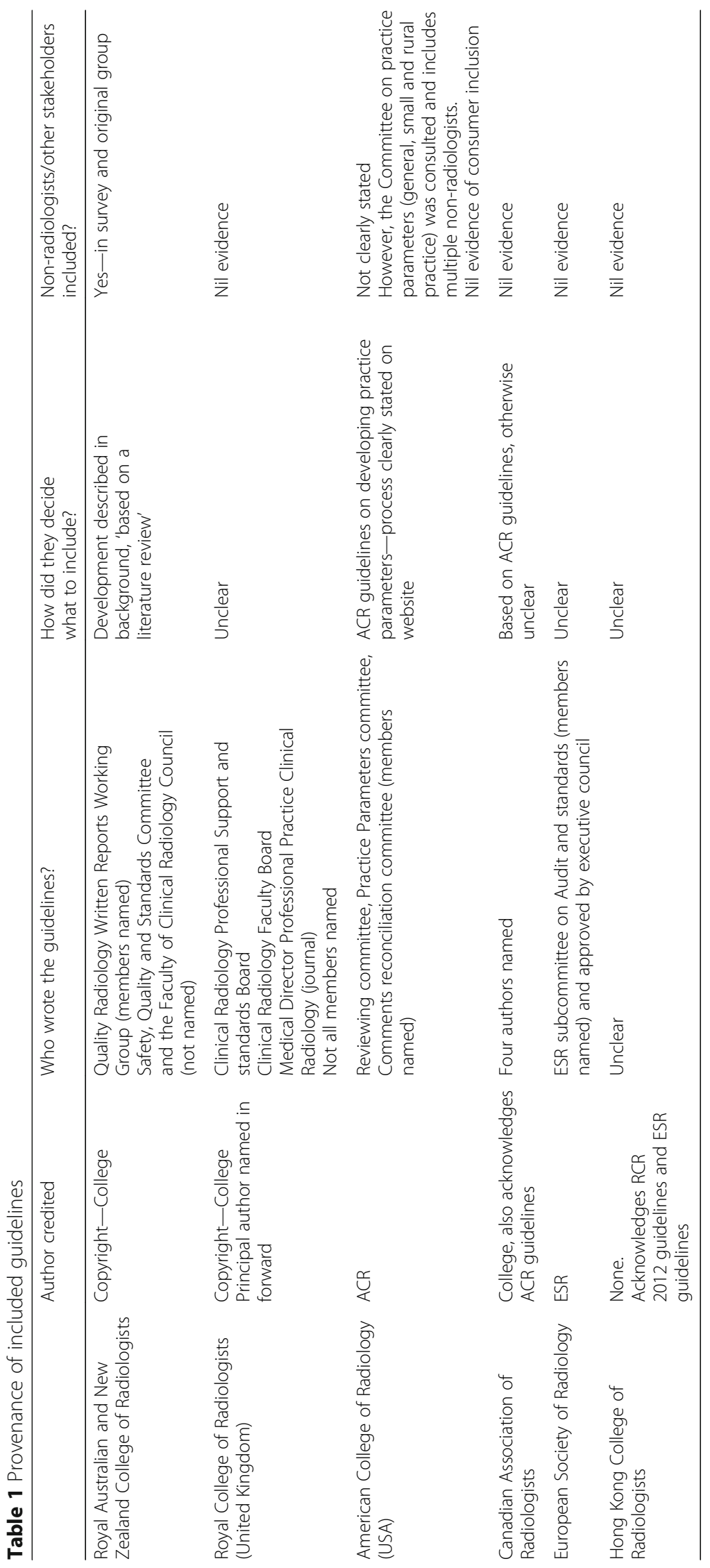


project managed by RANZCR resulting in an evidencebased guideline for the written radiology report [12]. The most recent RANZCR guidelines, included in this review [7], were preceded by an online survey of clinical radiologists with updates to the previous version clearly identified [18]. This was the only guideline to include a consumer as part of the development process and one of two (the other being the ACR) to include nonradiologist stakeholders in guideline development.

\section{Items covered across the guidelines}

All guidelines included basic suggestions regarding items to include in a radiology report (Table 2), and most with the exception of the HKCR suggested the following reporting sequence: clinical information, relevant findings, addressing the clinical question, providing differential diagnoses where required, and conclusion. The RANZCR guidelines included all the recommendations for written radiology reports regarding technical information and content based upon the template which was developed for this purpose. The HKCR guidelines were most limited, with a focus on timeliness and communication methods for radiological findings rather than report content. All other guidelines recommended the inclusion of technical information such as technique, examination quality, comparison with prior studies and procedural details. The same five guidelines recommended information regarding clinical history, relevant or abnormal findings, addressing the clinical question, differential diagnosis and conclusion. All six guidelines discussed recommendations for further testing or treatment, but only three recommended reporting normal findings $[7,13,15]$. Documentation of any discrepancies between an initial and final report was recommended in three guidelines $[6,7,16]$.

\section{Target audience for report}

All guidelines emphasise the need for accuracy, consider the referring physician the main audience and provide structure around language required. All encourage 'actionable' reporting, where radiology images are transformed into reports that assist patient care and influence outcome [19]. Four guidelines recommend the use of terminology should consider the referring clinician's background and not be overly technical $[6,7,13,15]$. Only two guidelines explicitly note patients and/or their carers may view results and recommend this be considered in reporting $[7,13]$.

\section{Discussions of clinical certainty}

Three guidelines $[7,13,16]$ discuss reporting with confidence or certainty. All guidelines make some reference

Table 2 Comparison of advice to radiologists regarding items to include in imaging findings

\begin{tabular}{|c|c|c|c|c|c|c|}
\hline & $\begin{array}{l}\text { Royal Australian and New } \\
\text { Zealand College of } \\
\text { Radiologists }\end{array}$ & $\begin{array}{l}\text { Royal College of } \\
\text { Radiologists (UK) }\end{array}$ & $\begin{array}{l}\text { American College } \\
\text { of Radiology }\end{array}$ & $\begin{array}{l}\text { Canadian Association } \\
\text { of Radiologists }\end{array}$ & $\begin{array}{l}\text { European Society } \\
\text { of Radiology }\end{array}$ & $\begin{array}{l}\text { Hong Kong } \\
\text { College of } \\
\text { Radiologists }\end{array}$ \\
\hline \multicolumn{7}{|l|}{ Technical information } \\
\hline Patient demographics & $\checkmark$ & $\checkmark$ & $\checkmark$ & $\checkmark$ & & \\
\hline Report status & $\checkmark$ & $\checkmark$ & $\checkmark$ & $\checkmark$ & & \\
\hline $\begin{array}{l}\text { Comparison with prior } \\
\text { studies }\end{array}$ & $\checkmark$ & $\checkmark$ & $\checkmark$ & $\checkmark$ & $\checkmark$ & \\
\hline Technique & $\checkmark$ & $\checkmark$ & $\checkmark$ & $\checkmark$ & $\checkmark$ & \\
\hline Procedural description & $\checkmark$ & $\checkmark$ & $\checkmark$ & $\checkmark$ & $\checkmark$ & \\
\hline Examination quality & $\checkmark$ & $\checkmark$ & $\checkmark$ & $\checkmark$ & $\checkmark$ & \\
\hline \multicolumn{7}{|l|}{ Content } \\
\hline $\begin{array}{l}\text { History/clinical } \\
\text { information }\end{array}$ & $\checkmark$ & $\checkmark$ & $\checkmark$ & $\checkmark$ & $\checkmark$ & \\
\hline $\begin{array}{l}\text { Relevant or abnormal } \\
\text { findings }\end{array}$ & $\checkmark$ & $\checkmark$ & $\checkmark$ & $\checkmark$ & $\checkmark$ & \\
\hline Normal findings & $\checkmark$ & $\checkmark$ & & & $\checkmark$ & \\
\hline $\begin{array}{l}\text { Addressing the clinical } \\
\text { question }\end{array}$ & $\checkmark$ & $\checkmark$ & $\checkmark$ & $\checkmark$ & $\checkmark$ & \\
\hline Differential diagnosis & $\checkmark$ & $\checkmark$ & $\checkmark$ & $\checkmark$ & $\checkmark$ & \\
\hline Conclusion & $\checkmark$ & $\checkmark$ & $\checkmark$ & $\checkmark$ & $\checkmark$ & \\
\hline $\begin{array}{l}\text { Testing or treatment } \\
\text { recommendations }\end{array}$ & $\checkmark$ & $\checkmark$ & $\checkmark$ & $\checkmark$ & $\checkmark$ & $\checkmark$ \\
\hline $\begin{array}{l}\text { Discrepancy } \\
\text { documentation }\end{array}$ & $\checkmark$ & & $\checkmark$ & $\checkmark$ & & \\
\hline
\end{tabular}


to the report being 'clear' [13-15] or advocate for brevity [7], and most suggest that the final report should be carefully reviewed to ensure there are no 'confusing or conflicting statements' [16]. Two guidelines make some reference to the readability of the report [7, 15], although the ESR guidelines merely suggest avoiding 'long descriptions of limited use to the referrer'. The RANZCR guidelines make direct reference to readability, which appears to be used interchangeably with the notion of clarity. However, this is not clearly defined in the guidelines or the papers on which the guidelines were based $[12,17,18]$. One guideline suggests including 'a conclusion or summary of the key findings in the clinical context' [13]. No guidelines in this review considered provision of lay summaries aimed at patients (Table 3).

\section{Discussion}

Based upon the six English language guidelines we were able to access, most tend to focus on structure of the report and technical information. Three guidelines encourage radiologists to consider the specialty and background of the referring clinician, while two acknowledge that patients may access their reports. Recommendations regarding format and language are inconsistent between guidelines. Only one guideline suggests the inclusion of clinical context [13], and no guideline recommends inclusion of a lay summary for patients. All guidelines suggest providing recommendations for further testing or treatment where appropriate.

Imaging reports are powerful. Radiologist recommendations in the report influence whether patients are referred for further testing [20], while report reminders regarding evidence-based practice can result in changes in prescribing [21, 22] and imaging referrals [23]. Despite this, only the RCR and RANZCR guidelines acknowledge that the way the imaging report is presented can impact patient management. The RCR guidelines state the purpose of a radiology report is to provide an accurate interpretation of images in a format that will prompt appropriate care for the patient' [13], and the RANZCR guidelines acknowledge the radiology report '...has an important impact on decisions about further investigation and management. Its form and content can be influential in reducing harm to patients...' [12]. With increasing accessibility of sensitive imaging modalities such as CT and MRI, the likelihood of identifying unexpected or incidental anatomical abnormalities has increased. Such incidental findings can be more common than the condition for which the imaging is being performed to detect [24]. While detailed reporting can enable the clinician to match radiological features to the patient's symptoms, with increasing detection of low-risk incidental findings comes a need to ensure imaging reports convey findings in a manner that enables accurate clinical decision-making and minimises potential patient harms from overdetection.

Structured reporting was discussed by four of the guidelines in this review $[6,7,15,16]$, although in one it is discussed as a potential future development [15] and in two it was suggested that any structured report should include the information included in that guideline $[6,16]$. Only the RANZCR guidelines considered structured reporting in any depth, stating 'Standardised....templates should be developed where they are likely to improve the quality of communication, and in particular, to meet the content requirements of specific referrer groups'. This ambiguity may be reflected in one Australian survey, where only $32.5 \%$ of oncologists reported regularly receiving structured reports, and 21\% never received them, despite expressing a strong preference for such reports [25]. Alongside being a possible solution to radiology report interpretation issues such as error rate [26] and clarity [27] and for clinical situations such as surgical planning [28], clinicians can extract information from structured reports more easily $[29,30]$ and it can improve agreement between clinicians regarding the interpretation of findings [31].

Providing structured reports alone may not be enough. Primary care physicians require certainty and clinical context from radiology reports. They prefer clear indications of the meaning of radiology terminology, likelihood of disease and clinical relevance of findings [32], including the normal sizes of anatomical structures [33]. Three guidelines in this review suggest using terminology that is widely understood or appropriate to the background of the referring clinician, and three discuss conveying confidence and certainty, but only one recommends clear statements regarding the likelihood of disease. Clinicians are more likely than radiologists to prefer the inclusion of negative findings [34], something considered only by the RANZCR guidelines. Although all guidelines recommended giving treatment or management suggestions in the report, only primary care physicians appreciate this information [35], and when suggestions are given, most clinicians feel obliged to follow recommendations [36].

Although patients desire access to their report [37], and are increasingly receiving it through their electronic medical records, only two guidelines consider the patient, and only to state that the reporting radiologist should consider that the patient may read the report. Methods to reduce patient distress and anxiety that have been explored include rewording imaging reports to use simpler and more neutral language [38], including patient-oriented explanations of complex medical terms along with diagrams $[39,40]$, and lay language summaries [41]. Insertion of benchmark epidemiological data providing information similar to normal ranges for 


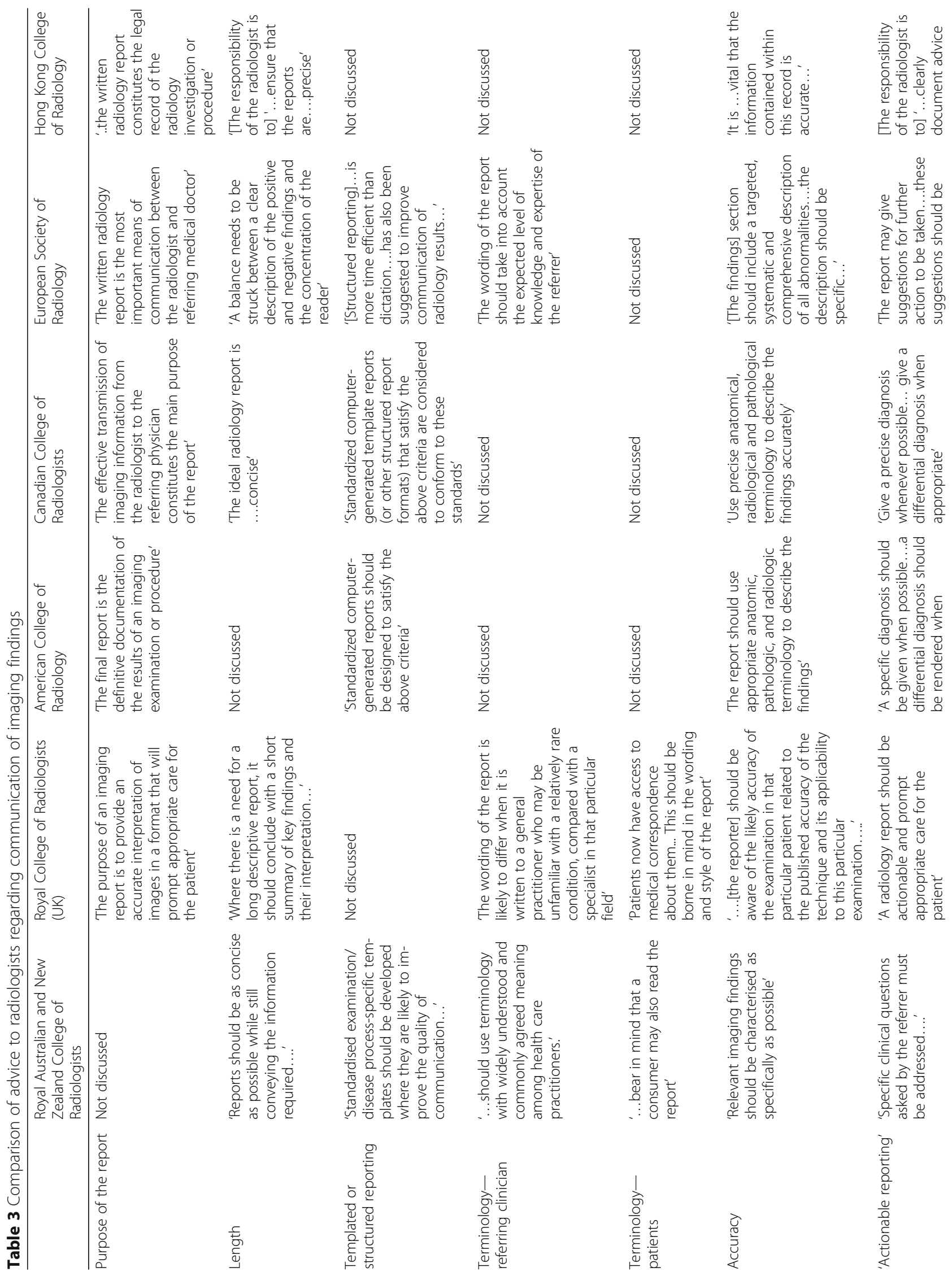




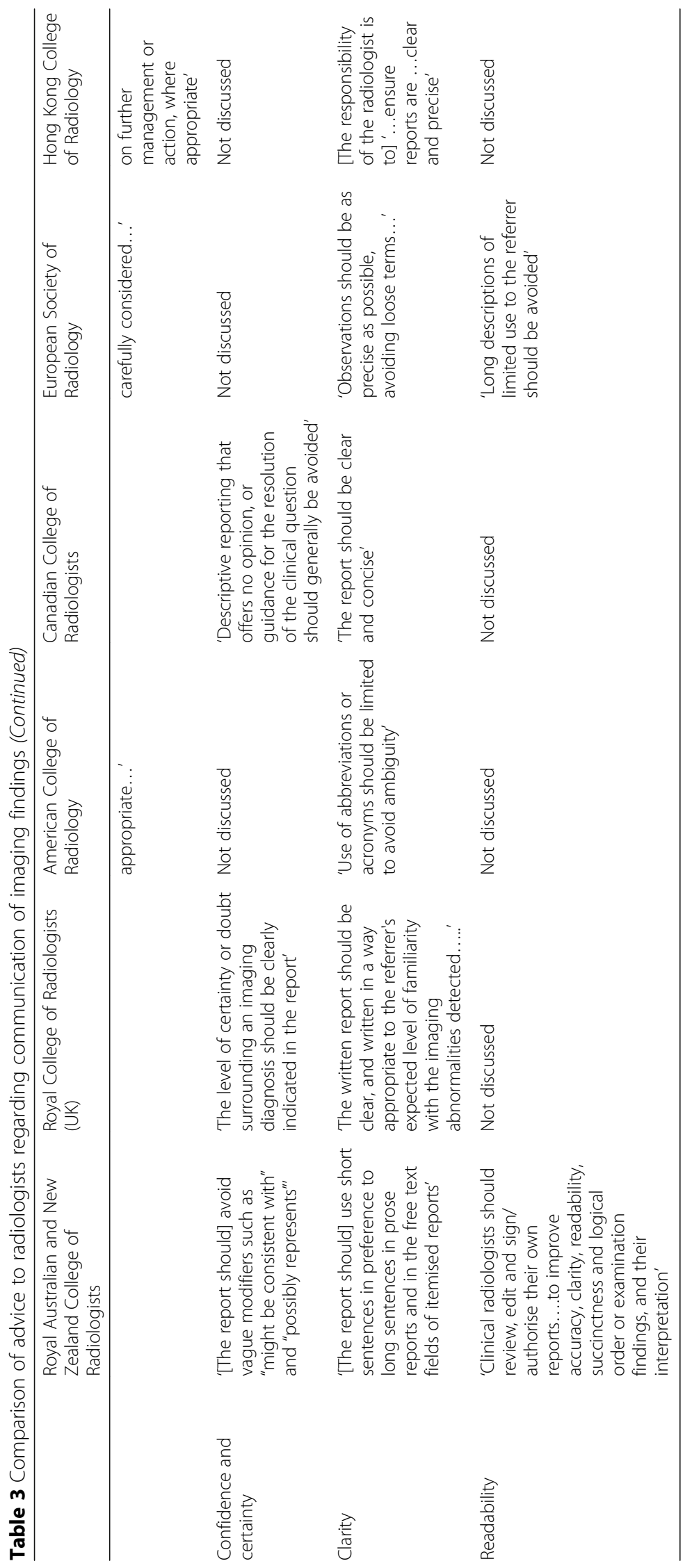


laboratory tests has also been proposed and investigated $[42,43]$. No guidelines in this review suggested aiming reports at a specific literacy level, or using reporting techniques preferred by patients undergoing imaging.

This paper has a number of strengths and limitations. The broad search strategy ensured that all professional association websites were searched and that any published guidelines were identified. Our study is limited to guidelines produced by professional member bodies and may not represent all reporting guidelines used by radiologists. The inclusion of only English language documents may mean our results are not generalizable to guidelines in other languages.

Current radiology reporting guidelines do not reflect the preferences expressed by referring clinicians and patients for radiology report comprehensibility. In practice, while radiology reports that conform with reporting guidelines are likely to be technically accurate, these may not be understood by the referring clinician and patient in the way intended. This may lead to anxiety and potentially unnecessary tests or treatment. Given the role radiology reports play in clinical decision-making, professional radiology member organisations have a responsibility to ensure that their guidance to members considers the clarity of radiology reports for referrers and patients. We recommend that future guideline development panels include end-users including consumers to ensure the requirements of these groups are met. This review identifies how guidelines can encourage radiologists to optimise the diagnostic imaging report to best meet the needs of referring clinicians and patients.

\section{Abbreviations}

ACR: American College of Radiology; CAR: Canadian Association of Radiologists; CT: Computed tomography; ESR: European Society of Radiology; HKCR: Hong Kong College of Radiology; MRI: Magnetic resonance imaging; PRISMA: Preferred Reporting Items for Systematic Reviews and MetaAnalyses; PRISMA-SCR: Preferred Reporting Items for Systematic Reviews and Meta-Analyses-Scoping Review; RANZCR: Royal Australian and New Zealand College of Radiologists; RCR: Royal College of Radiologists; TI-RADS: Thyroid Imaging Reporting and Data System

\section{Authors' contributions}

All authors contributed to the conception or design of the work and the writing and revision of the manuscript. CF and $A B$ extracted and analysed the data regarding the guidelines. The authors read and approved the final manuscript.

\section{Funding}

This study was supported by a National Health and Medical Research Council (NHMRC) programme grant (APP1113532). DOC is supported by an NHMRC TRIP Fellowship (APP1168749). JGJ is supported by the National Institute of Arthritis And Musculoskeletal And Skin Diseases of the National Institutes of Health under Award Number P30AR072572. The content is solely the responsibility of the authors and does not necessarily represent the official views of the National Institutes of Health. RB is supported by an NHMRC Senior Principal Research Fellowship (ID 1082138). No funding body had direct involvement in any facet of the design of the study, collection, analysis or interpretation of the data or writing of the manuscript.
}

\section{Availability of data and materials}

All guidelines used in this review are publicly available on the website of the relevant radiology college. Other data and materials will be shared by the authors upon reasonable request.

Ethics approval and consent to participate

Not applicable

\section{Consent for publication}

Not applicable

\section{Competing interests}

During the conduct of the review, JJ reports grants from the National Institute of Arthritis, Musculoskeletal and Skin Diseases (NIAMS/NIH) and relationships with Springer Publishing and the GE-Association of University Radiologists Radiology Research Academic Fellowship (GERRAF): Faculty Board of Review. The other authors declare no conflict of interest.

\section{Author details}

${ }^{1}$ Monash Department of Clinical Epidemiology, Cabrini Institute, 4 Drysdale St, Malvern, VIC 3144, Australia. ${ }^{2}$ Department of Epidemiology and Preventive Medicine, School of Public Health and Preventive Medicine, Monash University, Melbourne, VIC, Australia. ${ }^{3}$ Departments of Radiology, Neurological Surgery, School of Medicine and Health Services, School of Public Health, University of Washington, Seattle, WA, USA. ${ }^{4}$ Departments of Pharmacy and Orthopaedic \& Sports Medicine, School of Medicine, University of Washington, Seattle, WA, USA.

Received: 21 January 2020 Accepted: 31 March 2020

Published online: 05 May 2020

\section{References}

1. Wallis A, McCoubrie P (2011) The radiology report--are we getting the message across? Clin Radiol 66(11):1015-1022

2. Bosmans JM, Weyler JJ, Parizel PM (2009) Structure and content of radiology reports, a quantitative and qualitative study in eight medical centers. Eur J Radiol 72(2):354-358

3. Rosenkrantz $A B$ (2017) Differences in perceptions among radiologists, referring physicians, and patients regarding language for incidental findings reporting. AJR Am J Roentgenol 208(1):140-143

4. Khorasani R, Bates DW, Teeger S, Rothschild JM, Adams DF, Seltzer SE (2003) Is terminology used effectively to convey diagnostic certainty in radiology reports? Acad Radiol 10(6):685-688

5. Nickel B, Barratt A, Copp T, Moynihan R, McCaffery K (2017) Words do matter: a systematic review on how different terminology for the same condition influences management preferences. BMJ Open 7(7):e014129

6. American College of Radiology (2014) ACR Practice parameter for communication of diagnostic imaging findings.

7. The Royal Australian and New Zealand College of Radiologists (2017) Clinical radiology written report guide. The Royal Australian and New Zealand College of Radiologists: Sydney, Australia.

8. Arksey H, O'Malley L (2005) Scoping studies: towards a methodological framework. Int J Soc Res Methodol 8(1):19-32

9. Levac D, Colquhoun H, O'Brien KK (2010) Scoping studies: advancing the methodology. Implement Sci 5:69

10. Tricco AC, Lillie E, Zarin W et al (2018) PRISMA Extension for Scoping Reviews (PRISMA-SCR): checklist and explanation. Ann Intern Med 169(7): 467-473

11. Tessler FN, Middleton WD, Grant EG et al (2017) ACR Thyroid Imaging, Reporting and Data System (TI-RADS): white paper of the ACR TI-RADS Committee. J Am Coll Radiol 14(5):587-595

12. Goergen SK, Pool FJ, Turner TJ et al (2013) Evidence-based guideline for the written radiology report: methods, recommendations and implementation challenges. J Med Imaging Radiat Oncol 57(1):1-7

13. The Royal College of Radiologists (2018) Standards for interpretation and reporting of imaging investigations. The Royal College of Radiologists: London, UK.

14. Hong Kong College of Radiologists (2017) Guide on good medical practice for radiologists. 
15. European Society of Radiology (ESR) (2011) Good practice for radiological reporting. Guidelines from the European Society of Radiology (ESR). Insights Into Imaging 2(2):93-96

16. Canadian Association of Radiologists (2010) Standard for communication of diagnostic imaging finding. Canadian Association of Radiologists: Ottawa, Canada.

17. Pool F, Goergen S (2010) Quality of the written radiology report: a review of the literature. J Am Coll Radiol 7(8):634-643

18. Pool FJ, Siemienowicz ML (2019) New RANZCR clinical radiology written report guidelines. J Med Imaging Radiat Oncol 63(1):7-14

19. Boland GW, Enzmann DR, Duszak R Jr (2014) Actionable reporting. J Am Coll Radiol 11(9):844-845

20. Wickramarachchi BN, Meyer-Rochow GY, McAnulty K, Conaglen JV, Elston MS (2016) Adherence to adrenal incidentaloma guidelines is influenced by radiology report recommendations. ANZ J Surg 86(6):483-486

21. Heidenreich PA, Gholami P, Sahay A, Massie B, Goldstein MK (2007) Clinical reminders attached to echocardiography reports of patients with reduced left ventricular ejection fraction increase use of beta-blockers: a randomized trial. Circulation 115(22):2829-2834

22. Heidenreich PA, Chacko M, Goldstein MK, Atwood JE (2005) ACE inhibitor reminders attached to echocardiography reports of patients with reduced left ventricular ejection fraction. Am J Med 118(9):1034-1037

23. Eccles M, Steen N, Grimshaw J et al (2001) Effect of audit and feedback, and reminder messages on primary-care radiology referrals: a randomised trial. Lancet 357(9266):1406-1409

24. Hall WB, Truitt SG, Scheunemann LP et al (2009) The prevalence of clinically relevant incidental findings on chest computed tomographic angiograms ordered to diagnose pulmonary embolism. Arch Intern Med 169(21):19611965

25. Koczwara B, Tie M, Esterman A (2003) Are radiologists meeting the needs of Australian medical oncologists? Results of a national survey. Australas Radiol 47(3):268-273

26. Hawkins CM, Hall S, Zhang B, Towbin AJ (2014) Creation and implementation of department-wide structured reports: an analysis of the impact on error rate in radiology reports. J Digit Imaging 27(5):581-587

27. Johnson AJ, Chen MY, Zapadka ME, Lyders EM, Littenberg B (2010) Radiology report clarity: a cohort study of structured reporting compared with conventional dictation. J Am Coll Radiol 7(7):501-506

28. Norenberg D, Sommer WH, Thasler W et al (2017) Structured reporting of rectal magnetic resonance imaging in suspected primary rectal cancer: potential benefits for surgical planning and interdisciplinary communication. Invest Radiol 52(4):232-239

29. Gassenmaier S, Armbruster M, Haasters F et al (2017) Structured reporting of MRI of the shoulder - improvement of report quality? Eur Radiol 27(10): 4110-4119

30. Barbosa F, Maciel LM, Vieira EM, Azevedo Marques PM, Elias J, Muglia VF (2010) Radiological reports: a comparison between the transmission efficiency of information in free text and in structured reports. Clinics (Sao Paulo) 65(1):15-21

31. Bastuji-Garin S, Schaeffer A, Wolkenstein P et al (1998) Pulmonary embolism; lung scanning interpretation: about words. Chest 114(6):1551-1555

32. Espeland A, Baerheim A (2007) General practitioners' views on radiology reports of plain radiography for back pain. Scand J Prim Health Care 25(1): 15-19

33. Grieve FM, Plumb AA, Khan SH (2010) Radiology reporting: a general practitioner's perspective. Br J Radiol 83(985):17-22

34. Johnson AJ, Ying J, Swan JS, Williams LS, Applegate KE, Littenberg B (2004) Improving the quality of radiology reporting: a physician survey to define the target. J Am Coll Radiol 1(7):497-505

35. Ghali Eskander M, Leung A, Lee D (2010) Style and content of CT and MR imaging lumbar spine reports: radiologist and clinician preferences. AJNR Am J Neuroradiol 31(10):1842-1847

36. Gunn AJ, Sahani DV, Bennett SE, Choy G (2013) Recent measures to improve radiology reporting: perspectives from primary care physicians. J Am Coll Radiol 10(2):122-127

37. Cabarrus M, Naeger DM, Rybkin A, Qayyum A (2015) Patients prefer results from the ordering provider and access to their radiology reports. J Am Coll Radiol 12(6):556-562

38. Bossen JK, Hageman MG, King JD, Ring DC (2013) Does rewording MRI reports improve patient understanding and emotional response to a clinical report? Clin Orthop Relat Res 471(11):3637-3644
39. Cook TS, Oh SC, Kahn CE Jr (2017) Patients' use and evaluation of an online system to annotate radiology reports with lay language definitions. Acad Radiol 24(9):1169-1174

40. Hong MK, Feustel C, Agnihotri M, Silverman M, Simoneaux SF, Wilcox L (2017) Supporting families in reviewing and communicating about radiology imaging studies. Proc SIGCHI Conf Hum Factor Comput Syst 2017 : 5245-5256

41. Gunn AJ, Gilcrease-Garcia B, Mangano MD, Sahani DV, Boland GW, Choy G (2017) JOURNAL CLUB: structured feedback from patients on actual radiology reports: a novel approach to improve reporting practices. AJR Am J Roentgenol 208(6):1262-1270

42. Jarvik JG, BA Comstock, KT James et al (2015) Lumbar imaging with reporting of epidemiology (LIRE)--protocol for a pragmatic cluster randomized trial. Contemp Clin Trials 45:157-163

43. McCullough BJ, Johnson GR, Martin BI, Jarvik JG (2012) Lumbar MR imaging and reporting epidemiology: do epidemiologic data in reports affect clinical management? Radiology 262(3):941-946

\section{Publisher's Note}

Springer Nature remains neutral with regard to jurisdictional claims in published maps and institutional affiliations.

\section{Submit your manuscript to a SpringerOpen ${ }^{\circ}$ journal and benefit from:}

- Convenient online submission

- Rigorous peer review

- Open access: articles freely available online

- High visibility within the field

- Retaining the copyright to your article

Submit your next manuscript at $>$ springeropen.com 